\title{
Audiencias: de lo teórico a lo práctico. Tradiciones de un concepto falsable
}

\section{José Augusto Ventín Sánchez'}

DOI: 10.5294/pacla.2019.22.1.11

Reseña del libro: González-Bernal, M. I., Roncallo-Dow, S.; Arango-Forero, G.A. (2018). Estudiar las audiencias, tradiciones y perspectivas. Bogotá, Colombia: Universidad de La Sabana. 336 páginas, ISBN 978-958-12-0482-3

Si algo tienen de apasionante las ciencias sociales, tanto para los más racionalistas como para los más empiristas, es que se mueven en un falsacionismo cuya vigencia viene dada por las tendencias cientificistas que marca la economía de la investigación social; aunque, gracias al complejo cuestionador del académico científico, se retoman teorías que han sido aceptadas para volverlas a refutar. ¿Qué más falsable hay que las teorías sociales?

Así como algunos académicos excluyen la comunicación de la ciencia social y la consideran como una tecnología social, esta, epistemológicamente, se articula desde medios cognitivos y desde enfoques metodológicos para alcanzar, definir y conceptualizar su objeto de estudio. Es ahí, precisamente, donde la obra Estudiar las audiencias, tradiciones y perspectivas, se presenta como un tratado de gran valor académico, de sutil coherencia interpretativa y de nuevo enfoque falsable de la ecología de la audiencia del siglo XXI.

El libro está estructurado en cinco grandes apartados:

1. ¿Por qué (y qué) estudiar (de) las audiencias?

2. Seis tradiciones sobre el estudio de las audiencias

1 orcid.org/0000-0002-9217-0722. Universidad de La Sabana, Colombia. jose.ventin@unisabana.edu.co 
3. Estudios económicos de las audiencias

4. Pensar las audiencias hoy (de la exposición al engagement)

5. Articulando un modelo: el engageme

La obra comienza definiendo el objeto de estudio como un fenómeno cambiante en constante interrelación con su entorno, continúa analizando críticamente las formas en que se presentan los estudios de audiencias y las manifestaciones metodológicas que adquirieron, y concluye con una propuesta de enfoque holístico en el tratamiento y estudio de la audiencia prosumidora.

\section{El gran interrogante}

La mejor manera de abordar el objeto de estudio es con la pregunta ¿por qué (y qué) estudiar (de) las audiencias? A partir de ella los autores ubican al sujeto como problema moderno y evidencian el sentido cambiante que ha tenido como concepto, como fenómeno, en cuanto se conforma como una realidad construida desde los procesos en interacción e interrelación desde un punto de vista ecológico.

Mientras en Grecia el ágora "es el lugar del encuentro, la comunicación y la simultaneidad: es el lugar donde el griego determina su espacio, su tiempo y su propia condición humana” (p. 18), en el foro romano el ciudadano se concibe desde la institucionalidad del Estado y se mantendrá hasta la fragmentación y dispersión funcionales que se producen en el siglo XIX con la revolución tecnológica, que transformó la manera en que se comunica el sujeto con su entorno, lo cual contribuyó a conformar un "individuo desarraigado, carente de territorialidad” (p. 23) transformándose en masa. El "espacio y (el) tiempo son otros, el individuo se ha diluido y la ciudad se ha fragmentado, la plaza ha desaparecido, no física pero sí en su esencia. La realidad después de (esa) modernidad es otra” (p. 23). Modernidad que, según los autores, hará que se empiece a pensar en "los sujetos sociales en términos de audiencias”, donde la industrialización y la mercantilización de la comunicación traerán consigo un proceso reflexivo y analítico de estas (las audiencias), y en el que se evidenciará la complejidad, la diversidad y 
la necesidad de conocer este objeto de estudio desde múltiples abordajes y enfoques, tanto paradigmáticos como metodológicos.

\section{Sobre las seis tradiciones de estudio de las audiencias}

Las tradiciones son corrientes que atienden a intereses y dinámicas sistémicas para garantizar una estabilidad. En este caso, estudios de audiencias acordes a diferentes momentos históricos, no necesariamente cronológicos, entienden, o buscaban entender, el papel que el sujeto, la masa social, las audiencias o los públicos objetivos, deberían tener en contextos productivos, culturales o económicos específicos.

Del mismo modo, los autores de la obra que se reseña analizan las principales corrientes, los referentes investigativos y las principales características metodológicas de seis tradiciones de estudios de audiencias: la teoría sobre los efectos, estudios culturales y sobre la recepción, audiencias (de las ciencias sociales a los estudios humanistas) y estudios económicos sobre las audiencias.

En cuanto a la teoría sobre los efectos, destacar los términos, impactos, influencias y reacciones de diferentes denominaciones para analizar las consecuencias de los medios masivos. Es una teoría que plantea su pregunta central en el análisis de la estructura del mensaje propagandístico: si bien posteriormente pondrían su horizonte en la publicidad, la ficción y el entretenimiento; el medio sobre el que luego se centraron este tipo de estudios fue la televisión.

Como manifiestan los autores, la evolución entre una teoría y otra llega a ser muy difícil de definir, pues pueden ser "origen, reacción o complemento de otra” (p. 62). Por ejemplo, la teoría de los efectos y gratificaciones emana de la de teoría de los efectos, en la medida que esta se centra en la indagación del individuo más que en la del medio. Aquí, se estudia qué buscan las audiencias en el medio, más que qué efecto genera el medio en las audiencias. 
Si el siglo XX implicó nuevas formas y manifestaciones culturales, económicas, políticas y sociales, los estudios culturales, como tercera tradición sobre el estudio de las audiencias, que definen los autores de la obra, traerían nuevas perspectivas de análisis con el propósito de "interpretar todo este entorno cultural novedoso, cambiante, retados y especialmente mediáticos, en medio de una sociedad de posguerra" (p. 78), estudio de audiencias que, para los autores, dejó un importante legado en la medida que planteó un "sistema de aproximación al fenómeno comunicacional completamente ecléctico, que defendía la combinación de paradigmas provenientes de las ciencias sociales, del análisis del discurso mediático (semiótico, semántico y gramatical) y de postulados clásicamente humanistas" (p. 96).

Como se plantea a lo largo de la obra, los diferentes estudios se complementan entre sí; en ocasiones coexisten o son correlación unos de otros. Este es el caso de los estudios sobre la recepción, los cuales recogen aspectos de los estudios de efectos y culturales para capitalizar el concepto de audiencia activa y analizar la interrelación que se produce entre medios y receptores. Pasará lo mismo con los métodos de los diferentes campos de las ciencias sociales y las humanas: dialogarán entre sí y se redefinirán. Con la crítica literaria no habrá una "distinción metodológica [... ]. Por el contrario, busca integrar las conclusiones valiéndose de una variedad de métodos de crítica de textos lingüísticos, de teoría literaria y de retórica con el fin de justificar una o varias interpretaciones" (p. 115) de su objeto de estudio.

Todos estos análisis, con sus metodologías, han aportado desde distintos enfoques a analizar y conceptualizar el fenómeno de las audiencias. Según los autores (p. 131), no están obsoletos, pero ninguno se ha consolidado como definitivo en los campos de las ciencias sociales y humanas.

Por otro lado, de todos los estudios, surge uno desde un punto de vista convergente en las formas y los enfoques: los estudios económicos de las audiencias. En este, las audiencias son industrializadas y tipificadas; tienen intereses compartidos entre ellos (audiencia) y los medios 
para terminar convirtiéndose en el producto final de las industrias informativas. Sin embargo, estos estudios se encuentran en un cambio de paradigma (p. 146), en la medida que la convergencia tecnológica está transformando, o readaptando, los modelos de producción y distribución de las empresas informativas; asimismo, la interrelación entre éstas y los públicos objetivos.

\section{Un nuevo modelo para las audiencias de hoy}

Teniendo en cuenta lo anterior, precisamente, esas nuevas formas de interrelación entre los medios y las audiencias, en la que estas (las audiencias) tienen el "control y la capacidad de elección respecto a cuándo, dónde, qué y cómo consumir medios de comunicación" (p. 151) está obligando a la industria mediática a analizar de forma más precisa la manera en que se caracterizan y actúan desde sus hábitos y conductas, desde enfoques cuantitativos y cualitativos en contextos más complejos dados por la digitalización, la comunicación y la cultura convergente, desde la actividad interpretativa y de generación de sentido de las audiencias, desde la transnacionalización de los contenidos y sus consumos y desde la fragmentación de las audiencias y su autonomía (pp. 152-190).

Ante toda esta complejidad, los autores proponen un modelo de investigación de audiencias en el que se integran "dimensiones del sujeto y de su comportamiento de consumo" (p. 245). De esta forma se puede identificar la audiencia a partir del análisis de quién es (demográfica y psicológicamente), qué consume (exposición), cómo lo consume (hábitos y recepción), por qué lo hace (gratificaciones y expectativas) y qué efectos tienen en él (p. 245), modelo que se articula a partir del concepto de engagement: compromiso.

Elengagementes un metaconcepto (p.311) complejoy multidimensional que los autores aplican al estudio de las audiencias desde cuatro dimensiones (pp. 266-301): la experiencia del usuario (motivaciones y expectativas), como respuesta emocional, como resultado de proceso cognitivos (atención, recuerdo y aprendizaje) y desde los comportamientos y las participaciones. 
Es un metaconcepto que se puede investigar desde los distintos estudios de audiencias y desde sus metodologías; pero que, en últimas, como manifiestan los autores (p. 312), es una propuesta en la que se presenta un modelo integrador, frente a la fragmentación de estudios de audiencias que existía, con el que buscan abrir el debate porque... ¿qué más falsable hay que la misma comunicación? 